\title{
El uso del diccionario como componente estratégico en las clases de ele para alumnado sinohablante ${ }^{1}$
}

\author{
ISABEL GIBERT ESCOFET \\ Centro de Estudios Hispánicos \\ Universidad Rovira i Virgili \\ isabel.gibert@urv.cat \\ SANDRA IGLESIA MARTÍN \\ Centro de Estudios Hispánicos \\ Universidad Rovira i Virgili \\ sandra.iglesia@urv.cat
}

Resumen: El diccionario cumple una función importante en el proceso de aprendizaje de una LE (Lew, 2016). Cuando un alumno sinohablante está aprendiendo español ve la necesidad de usar el diccionario para verificar la ortografía o el significado de las palabras que desconoce (Tungmen Tu, 2010). Esto se evidencia en el hecho de que cuando llega a clase siempre trae consigo un diccionario. Los objetivos principales de este estudio son: (1) hacer un diagnóstico del uso que los estudiantes sinohablantes hacen de los diccionarios en clase; y (2) analizar la percepción que tienen dichos estudiantes de las ventajas y desventajas que representa el diccionario en el aula de lengua. Finalmente, se propone una línea de actuación docente en el ámbito del componente estratégico para optimizar el uso de diccionarios monolingües y bilingües en clase.

Palabras clave: ELE, sinohablantes, diccionarios, competencia estratégica

Abstract: The dictionary plays an important role in the learning process of a foreign language (Lew, 2016). The need to use the dictionary to verify the spelling or the meaning of the words that the Chinese student does not know when s/he is learning Spanish is beyond doubt (Tungmen $\mathrm{Tu}, 2012$ ). The fact that when a student arrives in class $\mathrm{s} / \mathrm{he}$ always brings a dictionary is an evidence. The main objectives of this study are: (1) to make a diagnosis of Chinese students dictionary use in class; and (2) analyze the students' perception of the advantages and disadvantages of the dictionary in the language classroom. In the conclusions of the work, a teaching approach is proposed in the scope of the strategic component to optimize the use of monolingual and bilingual dictionaries in class.

Key words: ELE, Spanish, Chinese learners, dictionary, strategic competence.

\footnotetext{
${ }^{1}$ Este estudio ha sido en parte posible a la financiación del proyecto «Diccionario de español para aprendices sinohablantes (fase primera)» (FFI2016-76417-P) del Grupo de Investigación en lexicografía y enseñanza de lenguas extranjeras (LEXELE) (2014 SGR 1288) de la URV
} 


\section{Introducción}

Aunque todavía falten estudios que demuestren la efectividad del uso del diccionario para el aprendizaje del léxico, si tomamos como referencia los trabajos de Lew (2016) sobre el uso del diccionario por parte de aprendices polacos de la lengua inglesa, veremos que está ampliamente aceptado que este cumple una función importante en el proceso de enseñanza-aprendizaje de una LE o L2. En el caso de los alumnos sinohablantes esto se constata desde el primer día de clase: cuando un alumno sinohablante está aprendiendo español ve la necesidad de usar el diccionario para, en líneas generales, asegurarse de cómo se escribe una palabra y también para consultar el significado de aquellas que desconoce (Tungmen Tu, 2010). Esto se evidencia en el hecho de que cuando un alumno llega al aula siempre trae consigo un diccionario que, o bien le resulta cómodo de transportar, o bien le ha sido aconsejado por algún profesor de español (cabe también la posibilidad de que sea el diccionario que haya encontrado en la tienda, sin haber consultado a ningún experto).

Este estudio es la primera fase de una investigación que pretende demostrar el efecto que tienen en los estudiantes de ELE las clases específicas destinadas al uso del diccionario, establecer qué tipo de actividades resultan más útiles para practicar el uso del diccionario a la vez que se aprende una LE y comprobar que el diccionario puede llegar a ser una herramienta que favorezca la competencia estratégica en los aprendices.

En este trabajo vamos a presentar el caso de los estudiantes sinohablantes de ELE. Estos estudiantes se caracterizan por no poder imaginar una clase de español sin diccionario. Sin embargo, esta necesidad que tienen de usar el diccionario no se ha visto, en la mayoría de los casos, apoyada por ningún tipo de orientación en su uso. Esta carencia formativa hace que no sean capaces de aprovechar al máximo las oportunidades de aprendizaje que les brinda esta herramienta.

Los objetivos principales de este estudio son tres: (1) hacer un diagnóstico del uso que los estudiantes sinohablantes hacen de los diccionarios en clase; (2) analizar la percepción que tienen dichos estudiantes de las ventajas y desventajas que representa el diccionario como herramienta en el aula de lengua, desde el punto de vista del desarrollo de sus estrategias de aprendizaje; y (3) proponer una actuación docente en la que el diccionario no solo es una herramienta de apoyo en la enseñanza-aprendizaje de ELE / EL2, sino que puede ser el eje vertebrador de la clase, como lo es habitualmente el manual.

\section{Reflexiones previas}

Mucho se ha escrito ya sobre la importancia del uso del diccionario en el aprendizaje de una lengua, por lo que no vamos a ahondar en el tema aquí. Lo que sí queremos señalar es que el uso del diccionario en el aula como parte del componente estratégico de la enseñanza de lenguas es un tema que no ha sido todavía ampliamente estudiado. Si a esto añadimos el hecho de que nos centramos en un perfil de alumno universitario y de nacionalidad china, la cuestión se complica.

Así, la relación que se establece entre el profesor, el alumno, el diccionario y el aula puede llegar a ser muy compleja. Como indica Rodríguez Gil (2006:2), el primer problema lo encontramos al pensar que el diccionario es una herramienta de uso individual y, en la mayoría de los casos, extraescolar; y el segundo problema vendría dado por los 
conocimientos que el alumno tiene sobre el diccionario (codificaciones, abreviaturas, información variada, entre otros).

Asimismo, hay que tener en cuenta que además de plantearnos elementos relacionados con el diccionario en sí y con su uso, vamos a tener que dilucidar, seguramente, qué tipo de diccionario es el más adecuado para nuestros alumnos. Normalmente, la disquisición no pasa de decidir si es mejor un diccionario monolingüe o un diccionario bilingüe para las distintas etapas del aprendizaje; en general, pensando en que en niveles A es mejor el bilingüe y, más adelante, podemos pensar en usar el monolingüe.

Esto es así para los estudiantes de español como lengua extranjera en general, pero, teniendo en cuenta la enorme distancia cultural que separa España y China, la relación entre diccionario-alumno-profesor se hace todavía más complicada. Según Mitre Ropero (2013: 2), la mayoría de sus alumnos de español en China utiliza traductores electrónicos en clase para la consulta de léxico, mientras que una minoría utiliza algunos diccionarios bilingües, como los de Yizhen, Sun de 2000 o el Diccionario moderno español-chino, chino-español, de varios autores.

Puesto que ninguna de las dudas de las que hemos hablado hasta ahora pueden resolverse sin acudir a los alumnos, decidimos crear una encuesta para recabar información sobre si los alumnos saben usar un diccionario (si alguien les ha enseñado), si prefieren trabajar con diccionario o no en clase, qué tipo de diccionario prefieren y por qué y en qué situaciones usan el diccionario.

\section{Investigación}

A partir de los datos aportados en el epígrafe anterior se llevó a cabo una investigación que nos ayudó cumplir con los objetivos iniciales: comprender mejor el uso que los estudiantes hacen de los diccionarios, diagnosticar las carencias que tienen en su uso desde el punto de vista del desarrollo de la competencia estratégica y proponer el uso del diccionario en clase, no solo como una herramienta de apoyo sino como eje vertebrador de la clase. Los datos obtenidos nos ayudaron a diseñar algunas actividades que fomentaran el desarrollo del elemento estratégico en los alumnos.

A continuación de desarrollará la contextualización y la metodología de trabajo que se ha llevado a cabo.

\subsection{Contextualización}

La experiencia con alumnos sinohablantes durante más de diez años nos llevó a preguntarnos por qué dependían tantísimo de los diccionarios, cómo eran esos diccionarios que utilizaban y qué hacía que tantas veces eligieran una palabra inadecuada para el contexto en el que querían utilizarla.

\subsection{Metodología}

La metodología adoptada para el estudio es una metodología mixta. A partir de una encuesta que nos permitió comprobar la generalización de ciertos problemas, analizamos la opinión de los propios estudiantes para poder llegar a una propuesta de acción docente que pueda fomentar la competencia estratégica con el uso que se hace del diccionario. 
El estudio se llevó a cabo en contexto universitario con una muestra de 56 estudiantes chinos universitarios que estaban cursando el tercer año de carrera en España. Su nivel de dominio del español oscilaba entre el B1 y el B2 y su edad iba de los 20 a los 23 años. La encuesta se administró a todos los alumnos de las asignaturas de "Comprensión y expresión escrita" y "Análisis e interpretación de textos escritos", como actividad obligatoria de una sesión de la asignatura "Comprensión y expresión escrita".

De acuerdo con Hartman (2000:385) uno de los aspectos que más ha contribuido al conocimiento de las necesidades y habilidades de los usuarios de diccionarios, ha sido la llamada "perspectiva del usuario". En esta primera fase del estudio se parte de una adaptación de algunas de las preguntas que utilizó Hartman (2000) en su estudio.

El cuestionario utilizado en este trabajo consta de 10 preguntas abiertas obligatorias, sobre los siguientes temas: (1) su formación en el uso del diccionario; (2) sus preferencias en lo relativo al uso del diccionario; (3) sus preferencias en cuanto al tipo de diccionario; (4) los problemas que tienen cuando encuentran una palabra en el diccionario y; (5) qué otras carencias perciben que tienen.

Las respuestas a estas preguntas son las que nos permiten establecer la importancia de la herramienta diccionario en el aula como elemento vital para el aprendizaje del español.

\section{Análisis de datos}

En este epígrafe presentamos los resultados más relevantes obtenidos en nuestro estudio, organizados en cuatro aspectos: la formación de los alumnos en el uso del diccionario, el uso de los diccionarios en el aula, las preferencias por diccionarios monolingües o bilingües y la información que los alumnos echan en falta en estas obras.

\subsection{Sobre la formación de los alumnos en el uso del diccionario}

El 62,5\% de los alumnos afirmaron haber tenido algún tipo de formación sobre el uso del diccionario. No obstante, no se trata de una formación específica, sino de unas orientaciones generales en algunas clases de español; sobre todo, en asignaturas que trabajan específicamente las destrezas escritas; por ejemplo, "Comprensión y expresión escrita" y "Análisis de textos" en el programa formativo que se imparte en España; y "Traducción", "Español sintético" o "Gramática", asignaturas que se imparten en las universidades chinas. En algunos casos, el contacto con la formación en el uso de los diccionarios se produce ya en las clases de primaria, con diccionarios monolingües, en clases de chino (L1).

En general, las respuestas muestran un gran desconocimiento del uso del diccionario. En ningún caso se especifican técnicas o estrategias específicas en su uso para el aprendizaje de lenguas y, además, los alumnos explicitan que sienten que los profesores españoles son incapaces de dotarles de esas estrategias porque desconocen totalmente la herramienta que, en su mayoría, utilizan en las clases (aplicación EShelper), así como el idioma chino.

Los alumnos destacan, sobre todo, el trabajo con el diccionario bilingüe, aunque las recomendaciones que recuerdan de sus profesores están relacionadas con la importancia del uso del diccionario monolingüe. Los diccionarios monolingües a los que hacen 
referencia, diccionarios sugeridos por los profesores, son: Diccionario en línea Clave, $D R A E$ en línea y una aplicación (no se especifica cuál, pero pensamos que es EShelper).

En cuanto a las actividades relacionadas con el uso del diccionario en el aula, los alumnos dicen haber llevado a cabo actividades como: (1) buscar el significado de palabras nuevas; (2) no utilizar el diccionario enseguida, intentar averiguar su significado según el contexto: leer el texto por primera vez sin diccionario, intentar averiguar el significado de las palabras por el contexto sin consultar el diccionario, si siguen sin entender la palabra, consultar a un compañero y, finalmente, si no consiguen comprenderlo buscar la palabra en el diccionario; (3) buscar palabras sinónimas y distribuirlas dependiendo de su carga semántica; (4) buscar equivalentes en el diccionario bilingüe y comprobar sus significados en el diccionario monolingüe; (5) traducir textos; (6) buscar las combinaciones, contextos de uso y los valores culturales de una palabra; (7) buscar inmediatamente, en el diccionario monolingüe, las palabras nuevas que van apareciendo en clase, pero solo en los diccionarios en papel, no en los electrónicos o en las aplicaciones.

\subsection{Sobre sus preferencias en el uso del diccionario}

Los resultados de la encuesta muestran que se establece una dicotomía entre diccionario en papel y diccionario en línea o aplicación móvil. La gran mayoría de estudiantes, el $85,7 \%$, ha usado alguna vez el diccionario en papel, pero muchos reconocen que les parece poco práctico y muy lento. De hecho, existe un nada despreciable $14 \%$ de los alumnos que afirman no haber usado nunca un diccionario en papel. Muchos dicen que el diccionario en papel es más útil en clase para memorizar, recordar y aprender palabras nuevas; entre otras cosas porque pueden tomar notas en el mismo diccionario. El 73\% de los alumnos no distinguen especialmente entre aplicaciones, diccionarios electrónicos y diccionarios en línea en lo que se refiere al uso.

Hasta la generalización de los teléfonos inteligentes, los estudiantes que llegaban de China para estudiar español venían con el diccionario de bolsillo Conciso Chino-Español / Español-Chino y algunos traían diccionarios electrónicos. A partir del año 2010, aproximadamente, el panorama ha ido cambiando: los diccionarios en papel y los diccionarios electrónicos han ido desapareciendo del aula para dar paso a las aplicaciones y a los diccionarios en línea.

Tras el análisis de las respuestas de nuestros alumnos, los diccionarios que se han podido registrar como más habituales en el uso son los siguientes: Eshelper, como aplicación; Nuevo diccionario Español-Chino y Nueva era Gran Diccionario Español-Chino, como diccionarios en papel y Diccionario Clave, Wordreference y DRAE, como diccionarios en línea ${ }^{2}$.

Como puede verse, la aplicación más generalizada en el uso es Eshelper. Sobre esta aplicación, los alumnos afirman que se trata de una aplicación flexible, cómoda y gratuita. Solo mencionan una desventaja: que el diccionario en el móvil puede ser un factor de distracción; parece que resulta fácil cambiar de aplicación al finalizar la consulta y seguir "jugando" con el teléfono sin continuar la tarea.

\footnotetext{
${ }^{2}$ Véanse las referencias de estos diccionarios en el epígrafe dedicado a la Bibliografía.
} 
En cuanto a los diccionarios en línea, los alumnos destacan: contenido más fiable; más información gramatical, información sobre sinónimos y antónimos, ejemplos, imágenes y fragmentos de vídeo que les ayudan a entender mejor y a recordar lo aprendido. También valoran el hecho de que en algunos de estos diccionarios existen foros de consulta en los que participan nativos que pueden resolverles dudas surgidas en la búsqueda de información.

Por lo que respecta a los diccionarios en papel, los alumnos los encuentran pesados, poco cómodos y poco prácticos, por lo que solo los consultan en casa o en la biblioteca, aunque admiten que tienen más acepciones, explicaciones, ejemplos y son más fiables. Una de las respuestas más repetidas, cuando se les pregunta sobre el uso del diccionario en papel, es que les ayuda a memorizar mejor las palabras y que aprenden más porque pueden tomar notas en el mismo diccionario. Los estudiantes destacan que esta es una de las estrategias que más les facilita el aprendizaje.

Un $50 \%$ de los encuestados afirma que les gusta trabajar sin diccionario cuando se trata de leer un texto en clase. Sobre todo, insisten en que si no tienen diccionario tienen que imaginar el significado de la palabra por el contexto y que, a veces, incluso, pueden dejarla de lado y, aun así, entienden todo el texto. Si tienen el diccionario, la tentación de buscar cada palabra les hace perder el tiempo y concentrarse en aquellas que, a veces, no son necesarias para entender la idea principal del texto.

Aquellos alumnos que afirman que prefieren trabajar con diccionario, el 37,5\%, comentan que les es más difícil entender el texto sin la ayuda de esta herramienta. Consideran que, si hay muchas palabras que no entienden, no pueden comprender el sentido general del texto.

\subsection{Sobre sus preferencias en cuanto al tipo de diccionario}

En lo que se refiere al uso del diccionario bilingüe, una gran mayoría de los alumnos, el $84 \%$, indica que no representa un problema, ya que el hecho de tener la información en su lengua materna les ayuda a entender todo mejor. No obstante, todos los encuestados destacan negativamente el hecho de que las equivalencias no siempre son exactas y no tienen la suficiente información como para saber cuál de ellas es la adecuada en cada caso.

Por lo que respecta al uso del diccionario monolingüe, el 78,5\% de los estudiantes considera que trabajar con este tipo de diccionario resulta muy difícil por el hecho de tener que entender una definición en español en la que aparecen muchas palabras nuevas. La posibilidad de entrar en un bucle de búsquedas que no les lleve a ningún sitio les parece suficiente como para decidir no trabajar con este tipo de obra.

\subsection{Problemas y carencias detectadas por los alumnos en el diccionario}

De las respuestas obtenidas en la encuesta, se desprende que prácticamente la totalidad de los alumnos, el 98,2\%, considera que necesita más información sobre una palabra una vez que la encuentra en el diccionario. La mayoría piensa en el diccionario bilingüe porque es el que más utiliza, como ya se ha señalado anteriormente. Por eso, cuando se les pregunta sobre el tipo de información que echan en falta, la respuesta que más se repite es que necesitan saber el uso de las palabras (léase, el contexto más adecuado para cada 
equivalente); tener ejemplos de uso de la palabra para saber tanto su uso sintagmático como su uso paradigmático (léase, también, combinaciones frecuentes de los equivalentes y contextos de uso) e imágenes.

\section{Propuesta didáctica}

Los datos analizados en el epígrafe 4 nos permiten pensar en la inclusión de estrategias de uso del diccionario en el aula, a través de una serie de actividades modelo que permitan un cambio en la visión del diccionario como mera herramienta de decodificación: el diccionario se convierte en el eje de la programación de aula.

Para mostrar a qué nos referimos con este tipo de trabajo y en consonancia con el tercer objetivo planteado (proponer el diccionario no solo como una herramienta de apoyo en la enseñanza-aprendizaje de ELE / EL2, sino como eje vertebrador de la clase), sirva la siguiente propuesta de acción. La propuesta integra, por una parte, el trabajo con varios aspectos que los estudiantes perciben como carencias en el momento de consultar el diccionario, como decidir qué palabra elegir de los equivalentes que se les presentan, por ejemplo, y, por otra, el uso de varios tipos de diccionarios: monolingües, bilingües, de sinónimos, etc., y, por último, la consulta de léxico, frases hechas y modismos, y sinónimos y antónimos en línea.

Partiendo de un extracto de la novela Como agua para chocolate de Laura Esquivel aportamos la siguiente secuenciación para trabajar en el aula:

\section{Lee el siguiente fragmento de la novela Como agua para chocolate de Laura Esquivel $^{3}$.}

Receta 1. Tortas de Navidad

Tita gozaba enormemente este paso, ya que mientras reposa el relleno es muy agradable gozar del olor que despide, pues los olores tienen la característica de reproducir tiempos pasados junto con sonidos y olores nunca igualados en el presente. A Tita le gustaba hacer una gran inhalación y viajar junto con el humo y el olor tan peculiar que percibía hacia los recovecos de su memoria. Vanamente trataba de evocar la primera vez que olió una de esas tortas, sin resultados, porque tal vez fue antes de que naciera. Quizá la rara combinación de las sardinas con el chorizo llamó tanto su atención que la hizo decidirse a renunciar a la paz del éter, escoger el vientre de Mamá Elena para que fuera su madre y de esta manera ingresar en la familia De la Garza, que comía tan deliciosamente y que preparaba un chorizo tan especial.

Esquivel (2001: 14)

a) ¿Te ocurre algo parecido con alguna comida? ¿Hay algún olor o sonido que te transporte inmediatamente a alguna situación, bien sea positiva o negativa? Coméntalo a la clase.

-Pues yo siempre que huelo a sardinas asadas me acuerdo de mis vacaciones de verano con mis padres.

-¿Ah, sí? Pues yo, ...

b) En Extremadura existe un pueblo en la provincia de Cáceres llamado Garrovillas de Alconétar1. En este pueblo hay un convento de monjas Jerónimas (devotas de San Jerónimo) en el que se hacen los Cagajones.

\footnotetext{
${ }^{3}$ Actividad introductoria de activación de conocimientos previos sobre el tema.
} 
¿Qué crees que son? Como ves, tienen un nombre bastante peculiar. ¿Te suena bien? ¿Qué te sugiere este nombre? ¿A qué lo asocias?

-Yo lo asociaría a algo que huele mal...

-Pues a mí me sugiere el olor del campo...

Como has visto, a la hora de comer, es muy importante, además del sabor, los colores, los olores... es decir, las sensaciones que nos despierta el plato que tenemos delante ${ }^{4}$.

a) En grupos y sin diccionario. Intentad encontrar alimentos que puedan asociarse a los siguientes adjetivos, cuantos más alimentos, mejor. Después veremos si todos asociáis los distintos adjetivos a los mismos alimentos.

\begin{tabular}{|l|l|l|l|}
\hline Amargo & Denso & Espumoso & Insípido \\
\hline Sabroso & Aromático & Rancio & Áspero \\
\hline Empalagoso & Pestilente & Crujiente & Jugoso \\
\hline Salado & Dulzón & Agrio & Picante \\
\hline
\end{tabular}

b) Clasifica ahora los adjetivos que has trabajado en el ejercicio anterior en la tabla siguiente, según el sentido con el que los relaciones:

\begin{tabular}{|c|c|l|c|c|}
\hline GUSTO & OÍDO & OLFATO & TACTO & VISTA \\
\hline & Crujiente & & Crujiente & \\
\hline
\end{tabular}

¿Coincides con tus compañeros? ¿Eres más sensible que ellos en relación a alguno de los sentidos?

c) Ahora, tu profesor o profesora te va a proporcionar un diccionario de sinónimos y antónimos. En parejas, elegid dos de los adjetivos anteriores y, con el diccionario, buscad si existe alguna relación entre estos y otros que signifiquen más o menos algo parecido (sinónimos), como dulce y dulzón o lo contrario (antónimos), como pestilente y aromático.

Un sinónimo de salado es sabroso y un antónimo es soso.

d) Después, intenta construir frases con los adjetivos que has elegido e intenta sustituirlos por los que has encontrado en el diccionario, como en el ejemplo:

¡Buaf! ¡Qué asco! La sopa está demasiado salada.

¡Buaf! ¡Qué asco! La sopa está demasiado sabrosa.

¿Significan lo mismo las frases que has construido? ¿Son correctas?

\footnotetext{
${ }^{4}$ Para saber decidir qué palabra elegir de los equivalentes que se les presentan en los diccionarios consultan.
} 
e) Busca ahora en un diccionario monolingüe los adjetivos con los que has trabajado y analiza si, realmente, son sinónimos o antónimos y si hay alguna información en el diccionario que pueda ayudarte a usar estos adjetivos.

¿Estás satisfecho con la información que has encontrado en el diccionario? Justifica tu respuesta

\section{Ahora observa: los adjetivos que aplicamos a la comida también pueden aplicarse a otros ámbitos de la vida 5 .}

a) Busca en las imágenes de Google los adjetivos que has trabajado o palabras de su familia, ¿a qué conceptos van asociados?

¿Los dedos son crujientes?

b) Acude al diccionario y busca en las definiciones de cada adjetivo si existe alguna correspondencia entre las imágenes y los distintos sentidos de cada palabra.

c) Has visto que no solo son adjetivos que sirven para calificar alimentos. Con la información que has conseguido hasta ahora y consultando de nuevo el diccionario busca frases en las que puedas usar los adjetivos o alguna palabra de la misma familia (verbo, sustantivo, etc.).

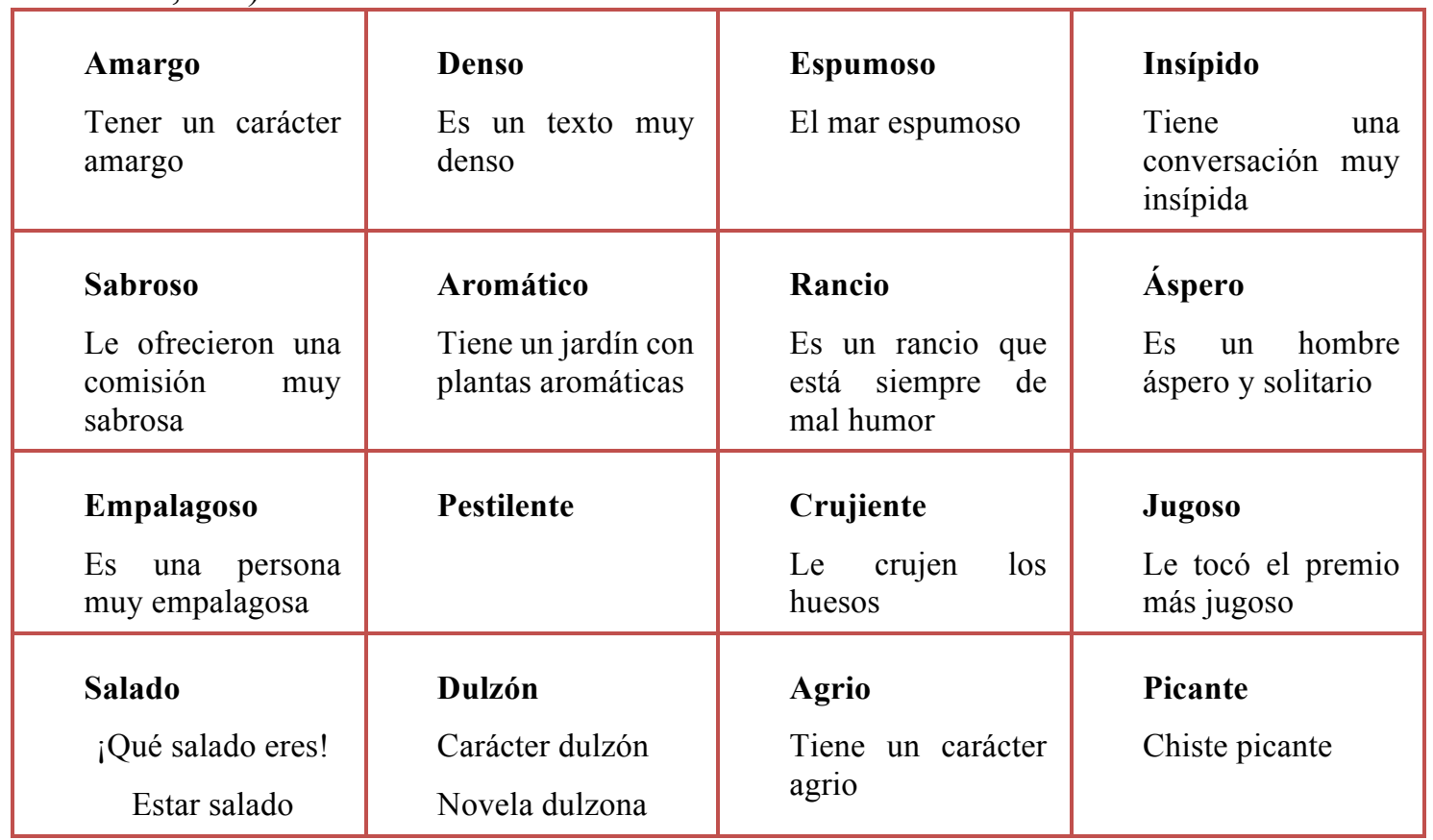

d) Busca los adjetivos en el diccionario bilingüe para contrastar estos usos con los usos de los adjetivos en tu propia lengua. ¿Se usan en los mismos contextos?

\section{¿Conoces frases hechas o modismos en los que aparezca la comida? ${ }^{6}$}

\footnotetext{
${ }^{5}$ Para trabajar la información contextual, el régimen sintagmático y paradigmático y las restricciones semánticas.

${ }^{6}$ Para la consulta de léxico, frases hechas y modismos.
} 
a) Mira en el diccionario si puedes encontrarlos con los siguientes alimentos y luego inventa una imagen que lo represente.

La leche se agria y una persona que tiene mala leche es una persona agria o con mal carácter.

b) Cuando hayas encontrado las frases hechas o modismos ilústralo (puedes hacer una foto, un dibujo o buscar una imagen en internet).

\section{Conclusiones}

Tras el análisis de los datos de la encuesta, se consigue un diagnóstico claro de los problemas derivados del uso del diccionario en el aula con estudiantes sinohablantes, cumpliendo así con el primer y el segundo objetivos planteados (hacer un diagnóstico del uso que los estudiantes sinohablantes hacen de los diccionarios en clase y analizar la percepción que tienen dichos estudiantes de las ventajas y desventajas que representa el diccionario como herramienta en el aula de lengua). En este sentido, las conclusiones que pueden extraerse del estudio son las siguientes:

1. La mayoría de los alumnos no han recibido instrucción para usar diccionarios de ningún tipo, lo que dificulta que sepan a qué diccionario acudir para resolver las dudas que les surgen.

2. El uso del diccionario en el aula tiene una estrecha relación con el nivel de lengua de los alumnos. Las respuestas obtenidas en las preguntas sobre trabajo con o sin diccionario, y diccionario monolingüe o bilingüe, para entender un texto en clase, demuestran que a menor nivel de lengua, mayor preferencia por trabajar con diccionario y que este sea bilingüe.

3. Los alumnos aceptan que el diccionario en papel es más completo y más exacto, pero prefieren usar aplicaciones o diccionarios en línea (aunque les lleve a error) por la inmediatez en la consulta.

4. Si bien el diccionario electrónico ha desaparecido completamente de entre los estudiantes chinos de ELE, el de papel lo siguen usando cuando están en casa o en la biblioteca, y las aplicaciones o diccionarios en línea se han convertido en las obras de uso cotidiano en cualquier lugar y cualquier situación.

Así pues, el trabajo con el diccionario en el aula no puede reducirse a un uso básico de descodificación de significados. Estas consideraciones nos llevan a afirmar que el profesor debe procurar que el alumno trabaje de forma explícita en el aula con el diccionario como estrategia de aprendizaje en dos sentidos: (1) creando actividades en las que el diccionario sea una fuente más de información para la creación de hipótesis y el aprendizaje de la lengua (no solo del léxico); (2) trabajando de forma cooperativa con el diccionario (tareas motivadoras en grupo).

El diccionario, así, deja de ser una herramienta individual y extraescolar para convertirse en un elemento clave del aprendizaje de la lengua y del trabajo cooperativo y la construcción del conocimiento. El trabajo con el diccionario en el aula es un elemento más del fomento de la competencia comunicativa, puesto que el diccionario es un input real más de la lengua que se lleva al aula para el desarrollo de la comunicación por parte del alumno. El hecho de trabajar con diferentes tipos de diccionarios es similar al hecho de trabajar en el aula con distintos tipos de textos o con distintos manuales. El alumno 
trabaja con el diccionario como manual de clase por lo que se conciencia de la optimización del uso del diccionario en su propio aprendizaje.

\section{Bibliografía}

EsQuivel, L. (2001). Como agua para chocolate. Barcelona: Bibliotex.

LEW, R. (2016). «Can a dictionary help you write better? A user of an active bilingual dictionary for Polish learners of English», International Journal of Lexicography, 29 (3), 353-366.

HARTMAnN, R.R.K. (2000). «European Dictionary Culture. The Exeter Case Study of Dictionary Use among University Students, against the Wide Context of the Reports and Recommendations of the Thematic Network Project in the Area of Languages (19961999)». En U. Heid, S. Evert, E. Lehmann, \& C. Rohrer (Eds.), Actas del IX EURALEX International Congress (pp. 385-391). Stuttgart: Institut für Maschinelle Sprachverarbeitung Universität Stuttgart.

Mitre Ropero, P. (2013). «Características para un diccionario monolingüe en China». SinoELE, 8, 1-16.

Real Academia Española (2014). Diccionario de la lengua española (23. ${ }^{\mathrm{a}}$ ed.). Recuperado de: http://www.rae.es/rae.html.

Rodríguez GiL, A.M. (2006). «Reflexiones sobre el uso del diccionario en la clase de ELE». Actas del I Congreso nacional ANPE (pp.1-9). Oslo: ANPE.

QIANYAN NETWORK (2017). EShelper (versión 6.2.1) [aplicación móvil]: https://play.google.com/store/apps/details?id=com.qianyan.eshelper\&hl=es.

TUNMENG, T. (2010). «Algunas consideraciones sobre el diccionario bilingüe españolchino en el aprendizaje de E/LE», Cuadernos Cervantes. Recuperado el 22/2/17, de: http://www.cuadernoscervantes.com/em_32_chino.html.

VV.AA. (2017). Wordreference. Recuperado el 22/2/17 de: http://www.wordreference.com/es.

VV.AA. (2012). Diccionario Clave SM. Recuperado el 22/2/17 de: http://clave.smdiccionarios.com/app.php.

VV.AA. (2006). Diccionario moderno español-chino, chino-español. Pequín: Foreign Language Teaching and Research Press.

YizHEN, Sun (2000). Nuevo diccionario chino-español. Pequín: Shangwu Yinshuguan. 